\title{
Creating a Pediatric Prehospital Destination Decision Tool Using a Modified Delphi Method
}

\author{
Jennifer F. Anders ${ }^{1, *}$, Jennifer N. Fishe ${ }^{2}$, Kyle A. Fratta ${ }^{1,3}$, Jessica H. Katznelson ${ }^{1}$, Matthew J. Levy ${ }^{4}$, \\ Richard Lichenstein ${ }^{5}$, Michael G. Milin ${ }^{4}$, Joelle N. Simpson ${ }^{6}$, Theresa A. Walls ${ }^{7}$ and Heather L. Winger ${ }^{8}$
}

check for

updates

Citation: Anders, J.F.; Fishe, J.N.; Fratta, K.A.; Katznelson, J.H.; Levy, M.J.; Lichenstein, R.; Milin, M.G.; Simpson, J.N.; Walls, T.A.; Winger, H.L. Creating a Pediatric Prehospital Destination Decision Tool Using a Modified Delphi Method. Children 2021, 8, 658. https://doi.org/ $10.3390 /$ children 8080658

Academic Editor: Johannes Mayr

Received: 28 June 2021

Accepted: 26 July 2021

Published: 29 July 2021

Publisher's Note: MDPI stays neutral with regard to jurisdictional claims in published maps and institutional affiliations.

Copyright: (c) 2021 by the authors Licensee MDPI, Basel, Switzerland. This article is an open access article distributed under the terms and conditions of the Creative Commons Attribution (CC BY) license (https:/ / creativecommons.org/licenses/by/ $4.0 /)$.
1 Department of Pediatrics, Johns Hopkins University, Baltimore, MD 21287, USA; frattaka@upmc.edu (K.A.F.); Jkatzne1@jhmi.edu (J.H.K.)

2 Department of Emergency Medicine, University of Florida-Jacksonville, Jacksonville, FL 32224, USA; Jennifer.fishe@jax.ufl.edu

3 Department of Emergency Medicine, University of Pittsburgh Medical Center-Harrisburg, Harrisburg, PA 15213, USA

4 Department of Emergency Medicine, Johns Hopkins University, Baltimore, MD 21287, USA; levy@jhmi.edu (M.J.L.); michaelgmillin@gmail.com (M.G.M.)

5 Division of Pediatric Emergency Medicine, University of Maryland School of Medicine, Baltimore, MD 21201, USA; rlichenstein@som.umaryland.edu

6 Department of Emergency Medicine, Children's National Hospital, Washington, DC 20010, USA; jnsimpso@childrensnational.org

7 Division of Emergency Medicine, Children's Hospital of Philadelphia, Philadelphia, PA 19104, USA; wallst1@email.chop.edu

8 Baltimore County Fire Department, Towson, MD 21286, USA; hlalexander380@gmail.com

* Correspondence: jander74@jhmi.edu; Tel.: +1-410-955-6143

\begin{abstract}
Decisions for patient transport by emergency medical services (EMS) are individualized; while established guidelines help direct adult patients to specialty hospitals, no such pediatric equivalents are in wide use. When children are transported to a hospital that cannot provide definitive care, care is delayed and may cause adverse events. Therefore, we created a novel evidencebased decision tool to support EMS destination choice. A multidisciplinary expert panel (EP) of stakeholders reviewed published literature. Four facility capability levels for pediatric care were defined. Using a modified Delphi method, the EP matched specific conditions to a facility pediatriccapability level in a draft tool. The literature review and EP recommendations identified seventeen pediatric medical conditions at risk for secondary transport. In the first voting round, two were rejected, nine met consensus for a specific facility capability level, and six did not reach consensus on the destination facility level. A second round reached consensus on a facility level for the six conditions as well as revision of one previously rejected condition. In the third round, the panel selected a visual display format. Finally, the panel unanimously approved the PDTree. Using a modified Delphi technique, we developed the PDTree EMS destination decision tool by incorporating existing evidence and the expertise of a multidisciplinary panel.
\end{abstract}

Keywords: emergency medical services (EMS); prehospital; pediatrics; emergency care; triage; transport; regionalization; specialty care

\section{Introduction}

More than one million pediatric patients are transported by prehospital emergency medical services (EMS) in the United States each year [1]. Following initial transport to an emergency department (ED), some pediatric patients then require secondary interfacility transport to specialty hospitals for definitive care [2]. Due to the wide variability in the pediatric capabilities of hospitals and the increasing centralization of pediatric care with the reduction of community pediatric inpatient beds, rates of secondary transport have dramatically increased, including for straightforward pediatric emergencies [3-6]. 
Pediatric patients are particularly susceptible to negative consequences of secondary transport $[7,8]$. Reported consequences include transport-related adverse events, increased lengths of stay, increased morbidity and delays in care [7-11]. Although transferring hospitals typically initiate interfacility transport rapidly, the average pediatric interfacility transport takes three hours to complete $[2,12,13]$. Even after arrival to definitive care, secondary transported children may still be subject to deleterious effects of undertreatment at the initial site or duplicate testing and imaging at the second site $[2,14,15]$.

Despite negative consequences from undertriage, most children transported by EMS do not need a high-capability pediatric facility. Overtriage increases travel burdens on families and represents an inefficient use of EMS resources, which could harm other patients who are also awaiting EMS care. Therefore, an ideal decision support tool would match pediatric patient needs with facility pediatric capability. For prehospital EMS providers, hospital destination choices are multifactorial, guided by patient condition, transport times, jurisdictional resources, local hospital capabilities, and patient/family preference. A statewide study from Florida found that one-third of pediatric transport decisions were due to patient/family preference [16]. Evidence-based guidelines (EBGs) have been developed to aid the EMS decision-making for adult patients suffering from trauma, myocardial infarction, stroke, psychiatric, and geriatric emergencies [17-22]. Those EBGs for direct transport protocols have demonstrated improved patient outcomes and EMS systems benefits [21-24]. While the all-ages trauma triage guidelines do address pediatric patients [17,25], rates of undertriage remain unacceptably high for injured children [26]. More significantly, no analogous guidelines exist for children with medical conditions.

To address that deficiency, the Pediatric Decision Tree (PDTree) was conceived as a pediatric prehospital destination decision support tool. The PDTree is designed to support EMS providers' decision-making and guide them to transport pediatric patients to a facility capable of providing definitive care. Recognizing the multi-factorial transport decision processes required of EMS, creation of the PDTree proceeded in steps combining available evidence and multidisciplinary consensus.

\section{Materials and Methods}

\subsection{Study Design}

The modified Delphi technique was used to create the PDTree tool through four iterative rounds of voting that took place between March and May of 2017. The modified Delphi method guides a multidisciplinary group of subject matter experts to arrive at a consensus [27]. That methodology has previously been applied to healthcare settings, including for EMS decision tools [28-31]. In the modified Delphi technique, the research team presents questions or scenario-based cues to an expert panel (EP), and EP members vote on each question/cue independently [27]. The modified Delphi technique differs from the traditional Delphi method in that the questions are predetermined by the study team based on existing evidence [32]. The project considered EP members as research volunteers, and the study was approved by the Institutional Review Board of Johns Hopkins Medicine.

Thirty-four experts were invited, and twenty-two agreed to participate in the PDTree EP. A quorum of 12 voting members from five distinct stakeholder groups was defined to maintain a balance of stakeholders through all voting rounds: three emergency physicians (EM), three pediatric emergency physicians (PEM), two EMS physicians who serve as EMS agency medical directors, three EMS providers, and one patient/family representative. At each meeting of the EP, each of these 12 stakeholder positions was represented by one of the $22 \mathrm{EP}$ members. EP members who were not designated as voting members for a specific meeting were invited to attend and contribute to the discussion.

\subsection{Systematic Review of the Literature}

To prepare for the modified Delphi process, three authors (KAF, JNF, JFA) performed a literature review utilizing multiple databases and the expertise of a medical librarian. MeSH terms are shown in Table 1. Search was limited to publications available in En- 
glish, but no date or publication-type filters were used. Included for further review were 60 articles relevant to non-trauma pediatric secondary transport or prehospital direct transport guidance. Studies of conditions addressed by existing all-ages trauma triage guidelines were specifically excluded, as the novel tool is intended to supplement and not contradict existing guidance. Each article was independently reviewed and rated by two of the three authors. Ratings were based on the quality of evidence, relevance, and importance to prehospital destination choice. The authors met to discuss differences of opinion; disagreements were mediated by the third author. After consensus, 47 articles were included in the evidence review provided to EP members. A summary of that review was published previously [33].

Table 1. Medical Subject Heading (MeSH) Terms used in PDTree Literature Review.

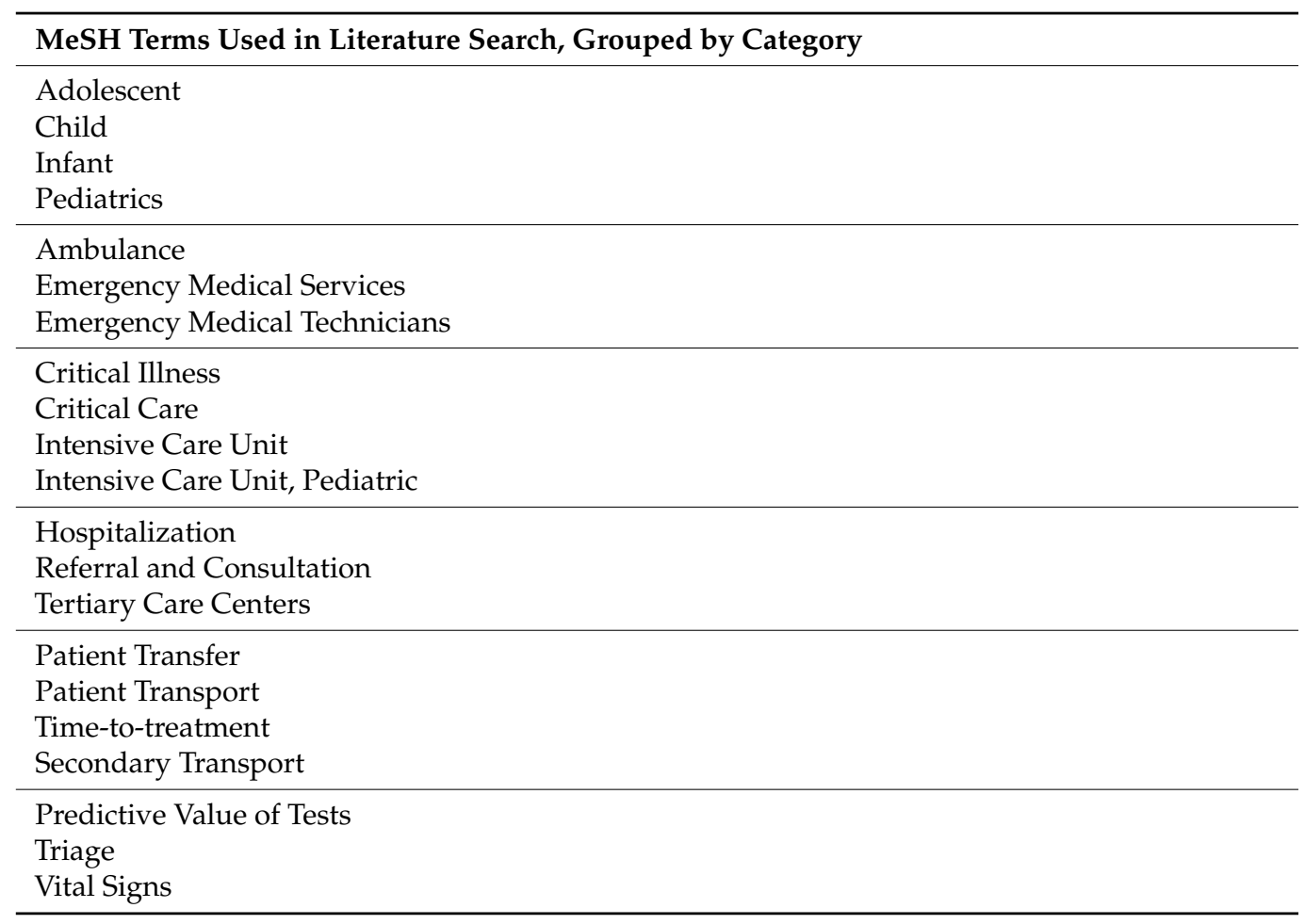

Additionally, results from three preliminary studies designed to inform the PDTree's development were presented to the EP. Those studies included a statewide assessment of interfacility transport patterns, a case-control study on conditions that resulted in secondary transport to a pediatric specialty center, and semi-structured interviews with EMS providers exploring current practice and attitudes toward pediatric transport destination choice [2,34].

Prior to the first meeting of the EP, members were provided with the literature review summary, copies of the 47 articles and summaries of the three preliminary studies. EP members were provided with a list of conditions identified by evidence review for potential inclusion on the tool and were asked to submit additional conditions for consideration.

\subsection{First in-Person Meeting (Round 1)}

Four levels of facility pediatric capability were created a priori-Closest Facility, Regional Pediatric Center, Comprehensive Pediatric Center, and Specialty/Trauma Pediatric Center. Those capability levels allow for hospital classification using publicly available information (Table 2).

A list of 17 conditions were presented to the panel members, and a timed discussion period was moderated by the study team. First, EP members considered if each condition warranted inclusion in the tool, and if so, to which facility capability level a pediatric patient with that condition should be transported (Table 3). 
Table 2. Definitions of Pediatric-Facility Capability Levels.

\begin{tabular}{cc}
\hline Hospital Classification & Pediatric Capabilities \\
\hline Specialty Center & $\begin{array}{c}\text { Trauma, burn, or other specialty center for pediatrics as } \\
\text { certified by state or national governing body }\end{array}$ \\
\hline Comprehensive Center & $\begin{array}{c}\text { The presence of a Pediatric Intensive Care Unit and } \\
\text { Pediatric OR/anesthesia services }\end{array}$ \\
\hline Regional Center & $\begin{array}{c}\text { The presence of a pediatric inpatient unit or pediatric } \\
\text { physician present on site 24-h per day }\end{array}$ \\
\hline Closest Facility & All other open facilities, including freestanding ED \\
\hline
\end{tabular}

Table 3. Conditions discussed by PDTree EP and voting results by rounds for inclusion on the PDTree and recommended destination-facility capability level.

\begin{tabular}{|c|c|c|c|c|c|}
\hline$\#$ & Condition & $\begin{array}{l}\text { Round } 1 \\
\text { Consensus for } \\
\text { Inclusion }\end{array}$ & $\begin{array}{l}\text { Pediatric Facility } \\
\text { Capability Level }\end{array}$ & $\begin{array}{l}\text { Round } 2 \\
\text { Consensus for } \\
\text { Inclusion }\end{array}$ & $\begin{array}{l}\text { Pediatric Facility } \\
\text { Capability Level }\end{array}$ \\
\hline 1 & Femur Fracture & Yes & Comprehensive & & \\
\hline 2 & $\begin{array}{c}\text { Long Bone Fracture with } \\
\text { Deformity }\end{array}$ & Yes & Comprehensive & & \\
\hline 3 & $\begin{array}{l}\text { Suspected C-spine } \\
\text { Injury }\end{array}$ & Yes & $\begin{array}{c}\text { Trauma/Specialty } \\
\text { Center }\end{array}$ & & \\
\hline 4 & $\begin{array}{l}\text { Respiratory Distress } \\
\text { with Oxygen } \\
\text { Requirement }\end{array}$ & No & $\mathrm{N} / \mathrm{A}$ & Yes-reworded & Regional \\
\hline 5 & $\begin{array}{l}\text { Respiratory Distress } \\
\text { with Tracheostomy }\end{array}$ & Yes & Comprehensive & & \\
\hline \multirow[t]{2}{*}{6} & $\begin{array}{l}\text { Non-traumatic Altered } \\
\text { Level of Consciousness }\end{array}$ & Yes & $\begin{array}{l}\text { No Level of Care } \\
\text { Determined }\end{array}$ & $\begin{array}{l}\text { Yes-dichotomized } \\
\text { by age }\end{array}$ & $\begin{array}{l}<2 \text { years old- } \\
\text { Comprehensive }\end{array}$ \\
\hline & & & & & $\begin{array}{c}>2 \text { years } \\
\text { old-Regional }\end{array}$ \\
\hline 7 & ALTE/BRUE & Yes & $\begin{array}{l}\text { No Level of Care } \\
\text { Determined }\end{array}$ & Yes & Regional \\
\hline 8 & Sepsis High Risk & Yes & Comprehensive & & \\
\hline 9 & Sepsis Low Risk & Yes & Regional & & \\
\hline 10 & Complex Wound & Yes & $\begin{array}{l}\text { No Level of Care } \\
\text { Determined }\end{array}$ & Yes-reworded & Comprehensive \\
\hline 11 & Eye Injury & Yes & $\begin{array}{c}\text { Trauma/Specialty } \\
\text { Center }\end{array}$ & & \\
\hline 12 & $\begin{array}{l}\text { Children with Special } \\
\text { Health Care Needs }\end{array}$ & Yes & Comprehensive & & \\
\hline 13 & Suspected Child Abuse & Yes & $\begin{array}{l}\text { No Level of Care } \\
\text { Determined }\end{array}$ & Yes & Regional \\
\hline 14 & DKA/Hyperglycemia & Yes & Comprehensive & & \\
\hline 15 & Shock & Yes & $\begin{array}{l}\text { No Level of Care } \\
\text { Determined }\end{array}$ & Yes-Reworded & Comprehensive \\
\hline 16 & Hypoxia & Yes & Do not include & & \\
\hline 17 & $\begin{array}{l}\text { Seizure with Medication } \\
\text { Administration by EMS }\end{array}$ & Yes & $\begin{array}{l}\text { No Level of Care } \\
\text { Determined }\end{array}$ & Yes-Reworded & Regional \\
\hline
\end{tabular}


After $10 \mathrm{~min}$, an electronic vote was held. Consensus was defined at $75 \%$ agreement for each question. If consensus was reached, the condition was either discarded or placed on the tool in the specified facility level. If consensus was not reached, an addition 10-min discussion period allowed EP members to suggest clarifications or specific subsets of the condition. One study team member moderated this discussion while another transcribed EP comments.

\subsection{Item Specifications and Verbiage (Round 2)}

The second round of EP voting sought to clarify included conditions that did not reach consensus on an optimal destination-facility capability level during the first round. During online voting, conditions were presented with alternate verbiage or additional specifications from the transcribed EP discussion along with the two facility capability levels that had the most votes in round 1 . Consensus was defined as $60 \%$ agreement for a single specification/verbiage option and destination level.

Four draft tools were developed based on the consensuses from previous voting sessions. The drafts contained the same content but differed in organization and formatting. In a second in-person meeting, the EP voted for a preferred draft and discussed including EMS systems considerations such as transport time or distance limits (beyond which EMS units should divert to a closer hospital), use of helicopter-EMS (HEMS) services, and online medical direction. Those considerations were incorporated into the final draft of the PDTree tool, which was presented electronically to the EP for voting.

\section{Results}

In the first voting round, 9 of the 17 conditions reached consensus for optimal pediatricfacility capability level. The panel rejected two conditions, "respiratory distress with an oxygen requirement" and "hypoxia", for lack of clarity. Six conditions had consensus for inclusion but did not reach consensus for destination-facility capability level. The EP consensus for each condition by voting round is detailed in Table 3.

In the second round of voting, alternate verbiage or additional specifications were made, and consensus was reached for 8 conditions (Table 3). The previously rejected respiratory distress condition was reworded as "respiratory distress with hypoxia or serious signs and symptoms". The condition "non-traumatic altered mental status" was dichotomized by age to create two distinct conditions. Table 4 shows the original and consensus wordings for the conditions with altered verbiage or specifications.

Table 4. PDTree conditions that were reworded by the expert panel.

\begin{tabular}{cc}
\hline Original Wording (Round 1) & Revised Wording (Round 2) \\
\hline $\begin{array}{c}\text { Seizure Requiring Medication Administration } \\
\text { by EMS }\end{array}$ & Seizure Requiring Benzodiazepine \\
\hline Complex Wound & Significant soft-tissue injury/complex wound \\
\hline $\begin{array}{c}\text { Non-Trauma Altered Mental Status with no } \\
\text { known seizure disorder }\end{array}$ & Dichotomized by age $<2$ yo and $\geq 2$ yo \\
\hline Shock & $\begin{array}{c}\text { Shock with Abnormal Pediatric Assessment } \\
\text { Triangle }\end{array}$ \\
\hline Respiratory Distress with Oxygen Requirement & $\begin{array}{c}\text { Respiratory Distress with Hypoxia or Serious } \\
\text { Signs and Symptoms }\end{array}$ \\
\hline
\end{tabular}

Three conditions generated robust discussion: shock, respiratory distress with an oxygen requirement, and altered mental status (non-trauma). While EP members felt strongly that patients in shock should be transported to a high-capability facility, they were reluctant to define vital signs specifications. Instead, the EP endorsed the inclusion of the validated prehospital Pediatric Assessment Triangle (PAT) by incorporating "abnormal PAT finding" in the "shock" condition [35]. Similarly, the "respiratory distress with an oxygen 
requirement" condition was revised to "respiratory distress with hypoxia or serious signs and symptoms" to allow EMS clinical decision-making. As with the PAT, this revision is supported by literature predicting which children require a higher level of care $[2,36,37]$. It also allows EMS providers to utilize the PDTree without pulse oximetry, which is not yet universally available in EMS.

In the discussion of altered mental status (AMS), EP members created subsets of patients by age (older or younger than 2 years), and the presence or absence of a known seizure disorder. Patients with apparent post-ictal AMS were determined appropriate for transport to the closest facility. For children 2 and older without seizure, EP consensus destination was a regional facility. For children younger than 2 years, the consensus destination was a comprehensive center due to concerns for possible abusive head trauma and higher likelihood of need for ICU admission.

At the second in-person meeting, the EP reviewed four draft tools. In a single vote, the EP reached consensus for the visual layout organizing conditions by destination-facility capability level in two columns (medical and trauma). Additionally, the EP discussed including recommendations for transport time or distance limits, helicopter-EMS (HEMS), and online medical direction. The EP voted for the tool to address those factors based on resource availability (e.g., "If feasible transport patient to ... center"; "consider aviation if faster or of clinical benefit" - Figure 1), but to leave specific parameters to the discretion of local medical directors and jurisdictional leadership. The EP unanimously voted to include the medical home as a destination for emergencies related to established conditions. The EP unanimously voted against prompts for online medical direction in an effort to respect EMS provider and agency autonomy and avoid delays in care [38]. After this meeting, a final draft tool was generated and presented to the EP, which was unanimously approved in online voting. The completed PDTree tool is presented in Figure 1. 


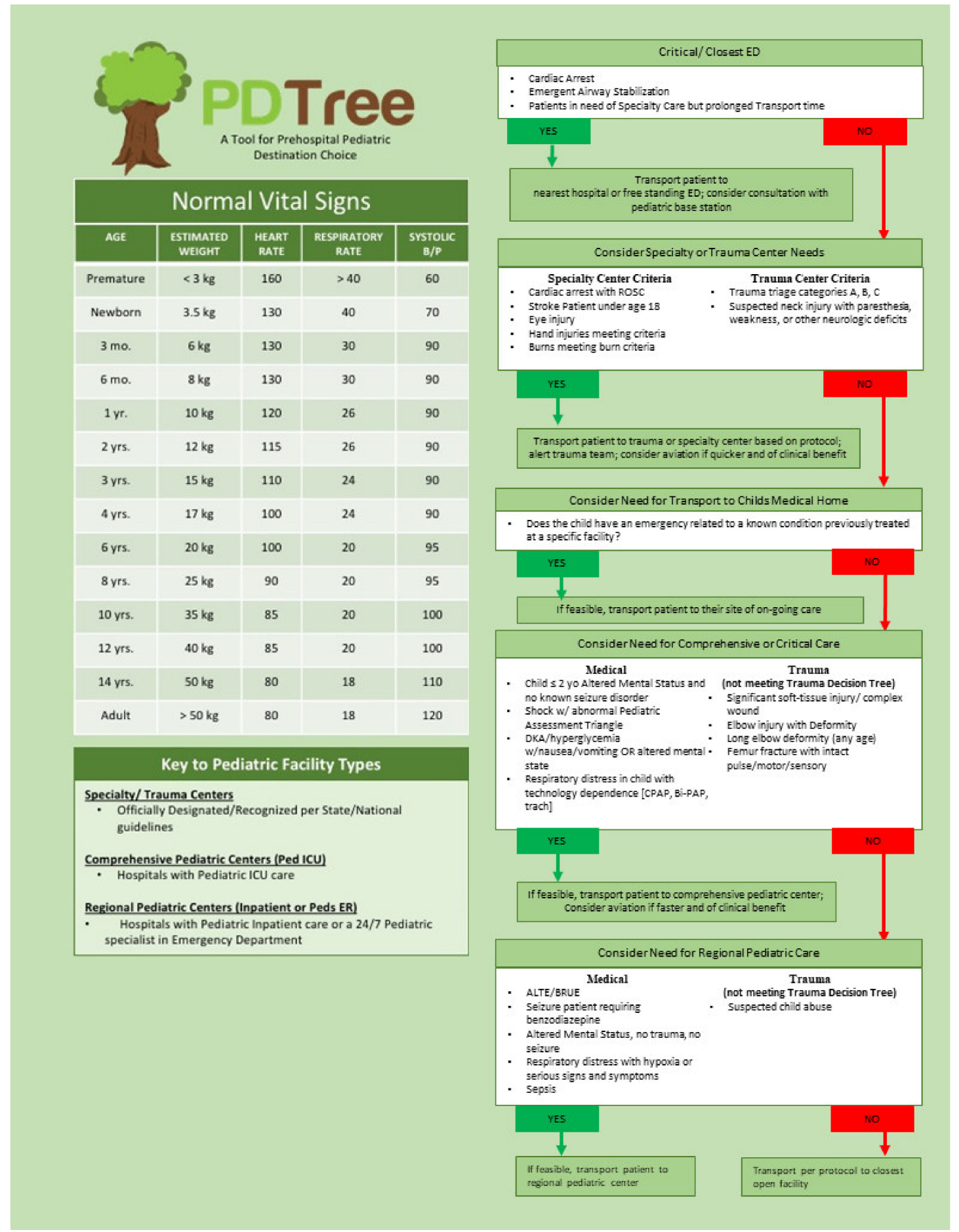

Figure 1. The Pediatric Decision Tree (PDTree) destination-decision support tool. Detailed criteria for Triage Categories and the Maryland Trauma Decision Tree referenced in the tool is found in [25] and are consistent with existing CDC trauma triage guidance [17]. Burn center criteria refer to the recommendations of the American Burn Association and can be found in [39].

\section{Discussion}

The PDTree is an evidence-based decision support tool designed for EMS providers to choose an optimal destination for prehospital pediatric patients. The primary goal of the PDTree is to increase the proportion of children directly transported to a facility capable of definitive care, thereby reducing secondary transport, delays in care, and 
adverse events. However, that goal is balanced against overburdening EMS resources and operational capabilities.

In the absence of evidence-based guidance, EMS providers' clinical discretion is used to determine the appropriate destination. That EMS subjective judgment is usually made on readily apparent clinical signs with an emphasis on the speed of decision-making [40]. Because of the emphasis on quick decisions and the difficulty in obtaining vital signs in pediatric patients, we developed a tool focused on clinical conditions and patient presentation rather than fixed physiologic criteria. Additionally, age-specific physiologic or vital signs used in isolation have been found to have only moderate predictive value in prehospital triage [41-44]. The EP chose to include age-based vital signs as a convenient reference on the tool (Figure 1).

In developing the PDTree, we explicitly defined pediatric-facility capability levels. However, definitions of pediatric-facility capability are not widely operative in EMS systems or hospital designation other than trauma/burn centers. The increasing centralization of pediatric resources and the opaque nature of true pediatric capabilities at individual hospitals poses a significant challenge for EMS providers to match pediatric patients' perceived needs from their prehospital viewpoint to actual hospital capabilities $[3,45,46]$. In the United States, trauma-center designation is rigorously defined, guided by a governing body, and integrated into prehospital guidelines [17,46]. For non-trauma conditions, there are many barriers to creation of rigorous criteria for tiered pediatric-facility designation, but some states have successfully done so. Our experience developing the PDTree supports the calls by others that the continuum of pediatric emergency care would benefit from facility designations at both the ED and hospital level [45-48].

While individual EMS provider clinical decision-making will always be important, it is often inadequate in isolation and highly variable between providers [49]. Evidencebased direct transport protocols and tools have been implemented for a variety of adult clinical scenarios, with improved triage and patient outcomes. By incorporating EMS providers' clinical findings within an evidence-based decision support tool, the PDTree aims to improve the efficiency of transporting more children to a destination capable of delivering definitive care.

An inherent concern with the modified Delphi technique is sustained and longitudinal expert participation. Because our EP members were busy professionals, we decided to empanel more than the minimum for quorum. We imposed a quorum for each stakeholder position to protect the relative position voting weight despite dropouts or inconsistent response rates between voting rounds. Another potential limitation to the modified Delphi technique is introduction of bias based on the cues provided to the EP members. We opted for non-presumptive language in forming our questions and allowed EP members to further define the question/cue for each condition.

Because the PDTree was developed by researchers and EP members from a single state, some elements may not be generalizable to other EMS systems. Maryland operates a statewide EMS system with shared protocols and operational resources, such as HEMS. Additionally, the three preliminary studies that were presented utilized Maryland data. Therefore, the PDTree may not directly translate for immediate operative use in other EMS systems. However, the PDTree was created with the intention that it could be adapted for use in diverse states and nations. The application of a PDTree tool to international systems may vary greatly with the scope of practice for EMS or the variable use of nurses or physicians in field response teams. However, the limited availability of pediatric specialty knowledge and care is universal. The open-ended language regarding use of HEMS or reasonable transport times/distances allows EMS systems to utilize the PDTree tool in the context of their operational resources. Additionally, diverse EMS systems may find it beneficial to utilize the process outlined in this paper to replicate consensus finding on optimal destination choice and adapt the PDTree's evidence-based guidelines to their location. 
The PDTree tool is expected to undergo revisions and adaptations in the future. Measurement of the impact of the tool includes patient health outcomes, system efficiency (reduction in secondary transport), and EMS operational resource costs. Expected revisions will address any concerns that arise in these measures. In addition, it is likely that future revisions will revise terminology or simplify language.

\section{Conclusions}

For decades, EMS providers have successfully utilized prehospital destination guidance for select high-risk adult conditions. The PDTree is presented here as a novel pediatric EMS destination decision tool. The modified Delphi technique allowed a multidisciplinary team of stakeholders to incorporate existing evidence with their own experience and reach consensus on the PDTree. The PDTree will undergo prospective testing to measure its impact on decision-making, patient outcomes, and EMS resource use.

Author Contributions: Conceptualization, J.F.A.; methodology, J.F.A., J.N.F., and K.A.F.; investigation, all authors (J.F.A., J.N.F., K.A.F., J.H.K., M.J.L., R.L., M.G.M., J.N.S., T.A.W. and H.L.W.); data curation, K.A.F.; formal analysis, J.F.A. and J.N.F.; writing-original draft preparation, J.F.A., J.N.F., and K.A.F.; writing—review and editing, all authors (J.F.A., J.N.F., K.A.F., J.H.K., M.J.L., R.L., M.G.M., J.N.S., T.A.W. and H.L.W.); funding acquisition, J.F.A. All authors have read and agreed to the published version of the manuscript.

Funding: This study was funded by the U.S. Health Resources and Service Administration (HRSA), Maternaland Child Health Bureau (MCHB) Emergency Medical Services for Children (EMSC) Targeted Issues Project (H34MC30232)).

Institutional Review Board Statement: This study was conducted according to the guidelines of the Declaration of Helsinki and was approved by the Institutional Review Board of Johns Hopkins Medicine (IRB00107565 approved 21 July 2016).

Informed Consent Statement: Informed consent was obtained from all subjects involved in the study.

Acknowledgments: The authors thank the Maryland EMS for Children (EMSC) state partnership program and its manager, Cyndy Wright-Johnson, for support in-kind and all stakeholders who voluntarily served as expert panel members. We are grateful for the assistance of Johns Hopkins Welch Library medical librarians with our systematic literature review.

Conflicts of Interest: The authors declare no conflict of interest. The funder had no role in the design of the study; in the collection, analyses, or interpretation of data; in the writing of the manuscript, or in the decision to publish the results.

\section{References}

1. Shah, M.N.; Cushman, J.T.; Davis, C.O.; Bazarian, J.J.; Auinger, P.; Friedman, B. The epidemiology of emergency medical services use by children: An analysis of the National Hospital Ambulatory Medical Care Survey. Prehosp. Emerg. Care 2008, 12, $269-276$. [CrossRef]

2. Fishe, J.N.; Psoter, K.J.; Klein, B.L.; Anders, J.F. Retrospective Evaluation of Risk Factors for Pediatric Secondary Transport. Prehosp. Emerg. Care 2018, 22, 41-49. [CrossRef]

3. Franca, U.; McManus, M.L. Availability of Definitive Hospital Care for Children. JAMA Pediatr. 2017, 171, e171096. [CrossRef] [PubMed]

4. Grube, M.E. The big squeeze in search of a sustainable future for suburban community hospitals. Healthc. Financ. Manag. 2006, 60, 56-65.

5. Stroud, M.H.; Trautman, M.S.; Meyer, K.; Moss, M.M.; Schwartz, H.P.; Bigham, M.T.; Tsarouhas, N.; Douglas, W.P.; Romito, J.; Hauft, S. Pediatric and Neonatal Interfacility Transport: Results from a National Consensus Conference. Pediatrics 2013, 132, 359-366. [CrossRef]

6. Li, J.; Monuteaux, M.C.; Bachur, R. Interfacility Transfers of Noncritically Ill Children to Academic Pediatric Emergency Departments. Pediatrics 2012, 130, 83-92. [CrossRef] [PubMed]

7. Odetola, F.O.; Mann, N.C.; Hansen, K.W.; Patrick, S.; Bratton, S.L. Source of admission and outcomes for criti-cally injured children in the mountain states. Arch. Pediatr. Adolesc. Med. 2010, 164, 277-282. [CrossRef]

8. Anders, J.F.; Adelgais, K.; Hoyle, J.D.J.R.; Olsen, C.; Jaffe, D.M.; Leonard, J.C. Comparison of outcomes for children with cervical spine injury based on destination hospital from scene of injury. Acad. Emerg. Med. 2014, 21, 55-64. [CrossRef] 
9. Cook, S.H.; Fielding, J.R.; Phillips, J.D. Repeat abdominal computed tomography scans after pediatric blunt abdominal trauma: Missed injuries, extra costs and unnecessary radiation exposure. J. Pediatr. Surg. 2010, 45, 2019-2024. [CrossRef]

10. Orr, R.A.; Venkataraman, S.T.; Cinoman, M.I.; Hogue, B.L.; Singleton, C.A.; McCloskey, K.A. Pretransport Pediatric Risk of Mortality (PRISM) score underestimates the requirement for intensive care or major interventions during interhospital transport. Crit. Care Med. 1994, 22, 101-107. [CrossRef] [PubMed]

11. Kanter, R.K.; Boeing, N.M.; Hannan, W.P.; Kanter, D.L. Excess morbidity associated with interhospital transport. Pediatrics 1992, 90, 893-898.

12. Ammon, A.A.; Fath, J.J.; Brautigan, M.; Mehta, R.; Matthews, J. Transferring patients to a pediatric trauma center: The trans-ferring hospital's perspective. Pediatr. Emerg. Care 2000, 16, 332-334. [CrossRef]

13. Harrison, T.; Thomas, S.H.; Wedel, S.K. Interhospital aeromedical transports: Air medical activation intervals in adult and pediatric trauma patients. Am. J. Emerg. Med. 1997, 15, 122-124. [CrossRef]

14. Walls, T.A.; Chamberlain, J.M.; Strohm-Farber, J.; Klein, B.L. Improving pretransport care of pediatric emergency patients: An assessment of referring hospital care. Pediatr. Emerg. Care 2010, 26, 567-570. [CrossRef]

15. Brinkman, A.S.; Gill, K.G.; Leys, C.M.; Gosain, A. Computed tomography-related radiation exposure in chil-dren transferred to a Level I pediatric trauma center. J. Trauma Acute Care Surg. 2015, 78, 1134-1137. [CrossRef]

16. McManus, K.; Finlay, E.; Palmer, S.; Anders, J.F.; Hendry, P.; Fishe, J.N. A Statewide Analysis of Reason for EMS' Pediatric Destination Choice. Prehosp. Emerg. Care 2020, 24, 672-682. [CrossRef] [PubMed]

17. Sasser, S.M.; Hunt, R.C.; Faul, M.; Sugerman, D.; Pearson, W.S.; Dulski, T.; Wald, M.M.; Jurkovich, G.J.; Newgard, C.D.; Lerner, E.B. Guidelines for field triage of injured patients: Recommendations of the National Expert Panel on Field Triage, 2011. MMWR Recomm. Rep. 2012, 61, 1-20.

18. Le May, M.R.; So, D.Y.; Dionne, R.; Glover, C.A.; Froeschl, M.P.; Wells, G.A.; Davies, R.F.; Maloney, J.; Marquis, J.-F.; Labinaz, M. A citywide protocol for primary PCI in ST-segment elevation myocardial infarction. N. Engl. J. Med. 2008, 358, 231-240. [CrossRef]

19. Kidwell, C.S.; Starkman, S.; Eckstein, M.; Weems, K.; Saver, J.L. Identifying stroke in the field. Prospective validation of the Los Angeles prehospital stroke screen (LAPSS). Stroke 2000, 31, 71-76. [CrossRef] [PubMed]

20. Leleu, H.; Capuano, F.; Ferrua, M.; Nitenberg, G.; Minvielle, E.; Schiele, F. Symptom-to-needle times in ST-segment elevation myocardial infarction: Shortest route to a primary coronary intervention facility. Arch. Cardiovasc. Dis. 2013, 106, 162-168. [CrossRef]

21. Cheney, P.; Haddock, T.; Sanchez, L.; Ernst, A.; Weiss, S. Safety and compliance with an emergency medical service direct psychiatric center transport protocol. Am. J. Emerg. Med. 2008, 26, 750-756. [CrossRef]

22. Vicente, V.; Sjöstrand, F.; Sundström, B.W.; Svensson, L.; Castren, M. Developing a decision support system for geriatric patients in prehospital care. Eur. J. Emerg. Med. 2013, 20, 240-247. [CrossRef]

23. Jollis, J.G.; Roettig, M.L.; Aluko, A.O.; Anstrom, K.J.; Applegate, R.J.; Babb, J.D.; Berger, P.B.; Bohle, D.J.; Fletcher, S.M.; Garvey, J.L. Implementation of a Statewide System for Coronary Reperfusion for ST-Segment Elevation Myocardial Infarction. JAMA 2007, 298, 2371-2380. [CrossRef]

24. Le May, M.R.; Wells, G.A.; So, D.Y.; Glover, C.A.; Froeschl, M.; Maloney, J.; Dionne, R.; Marquis, J.-F.; O’Brien, E.R.; Labinaz, $\mathrm{M}$. Reduction in mortality as a result of direct transport from the field to a receiving center for primary percutaneous coronary intervention. J. Am. Coll. Cardiol. 2012, 60, 1223-1230. [CrossRef]

25. Maryland Institute for EMS Systems. Trauma Decision Tree (Page 174) Maryland Protocols for Pre-Hospital Providers. Available online: https: / / www.miemss.org/home/Portals/0/Docs/Guidelines_Protocols/MD-Medical-Protocols-2019.pdf (accessed on 27 June 2021).

26. Lerner, E.B.; Cushman, J.T.; Drendel, A.L.; Badawy, M.; Shah, M.N.; Guse, C.E.; Cooper, A. Effect of the 2011 Revisions to the Field Triage Guidelines on Under- and Over-Triage Rates for Pediatric Trauma Patients. Prehosp. Emerg. Care 2017, 21, 456-460. [CrossRef] [PubMed]

27. Murphy, M.K.; Black, N.A.; Lamping, D.L.; McKee, C.M.; Sanderson, C.F.; Askham, J.; Marteau, T. Consensus development methods, and their use in clinical guideline development: A review. Health Technol. Assess. 1998, 2, 1-88. [CrossRef]

28. Eubank, B.H.; Mohtadi, N.G.; Lafave, M.R.; Wiley, J.P.; Bois, A.J.; Boorman, R.S.; Sheps, D.M. Using the modified Delphi method to establish clinical con-sensus for the diagnosis and treatment of patients with rotator cuff pathology. BMC Med. Res. Methodol. 2016, 16, 56. [CrossRef]

29. Kunz, D.; Pariyadath, M.; Wittler, M.; Askew, K.; Manthey, D.; Hartman, N. Derivation of a Performance Checklist for UltrasoundGuided Arthrocentesis Using the Modified Delphi Method. J. Ultrasound Med. 2017, 36, 1147-1152. [CrossRef]

30. Browne, L.R.; Shah, M.I.; Studnek, J.R.; Farrell, B.M.; Mattrisch, L.M.; Reynolds, S.; Ostermayer, D.G.; Brousseau, D.C.; Lerner, E.B. 2015 Pediatric Research Priorities in Prehospital Care. Prehosp. Emerg. Care 2016, 20, 311-316. [CrossRef]

31. Studnek, J.R.; Lerner, E.B.; Shah, M.I.; Browne, L.R.; Brousseau, D.C.; Cushman, J.T.; Dayan, P.S.; Drayna, P.C.; Kahn, C.A.; Stanley, R.M. Consensus-based Criterion Standard for the Identification of Pe-diatric Patients Who Need Emergency Medical Services Transport to a Hospital with Higher-level Pedi-atric Resources. Acad. Emerg. Med. 2018, 25, 1409-1414. [CrossRef]

32. Custer, R.L.; Scarcella, J.A.; Stewart, B.R. The Modified Delphi Technique-A Rotational Modification. J. Career Tech Educ. 1999, 15, 50-58. [CrossRef]

33. Fratta, K.A.; Fishe, J.N. EMS Pediatric Transport Safety and Secondary Transport. Available online: https://www.ncbi.nlm.nih. gov/books/NBK513234/ (accessed on 23 June 2021). 
34. Aledhaim, A.; Fishe, J.N.; Hirshon, J.M.; Anders, J.F. Pediatric Conditions Requiring Interfacility Transport from Emergency Departments: A Statewide Study of Regionalization. Pediatric Emerg. Care 2021, 37, e319-e323. [CrossRef]

35. Gausche-Hill, M.; Eckstein, M.; Horeczko, T.; McGrath, N.; Kurobe, A.; Ullum, L.; Kaji, A.H.; Lewis, R.J. Paramedics Accurately Apply the Pediatric Assessment Triangle to Drive Management. Prehosp. Emerg. Care 2014, 18, 520-530. [CrossRef] [PubMed]

36. Sahyoun, C.; Fleegler, E.; Kleinman, M.; Monuteaux, M.C.; Bachur, R. Early Identification of Children at Risk for Critical Care: Standardizing Communication for Inter-Emergency Department Transfers. Pediatr. Emerg. Care 2013, 29, 419-424. [CrossRef]

37. Freire, G.; Kuppermann, N.; Zemek, R.; Plint, A.C.; Babl, F.E.; Dalziel, S.R.; Freedman, S.; Atenafu, E.G.; Stephens, D.; Steele, D.W. Predicting Escalated Care in Infants with Bronchiolitis. Pediatrics 2018, 142, e20174253. [CrossRef]

38. Baker, J.; Cole, J. EMS, Medical Oversight of Systems. Available online: https:/ /www.ncbi.nlm.nih.gov/books/NBK526093/ (accessed on 25 June 2021).

39. American Burn Association. Burn Center Referral Criteria. Available online: https://ameriburn.org/wp-content/uploads/2017 /05/burncenterreferralcriteria.pdf (accessed on 20 July 2021).

40. Jones, C.M.C.; Cushman, J.T.; Lerner, E.B.; Fisher, S.G.; Seplaki, C.L.; Veazie, P.J.; Wasserman, E.B.; Dozier, A.; Shah, M.N. Prehospital Trauma Triage Decision-making: A Model of What Happens between the 9-1-1 Call and the Hospital. Prehosp. Emerg. Care 2016, 20, 6-14. [CrossRef]

41. Newgard, C.D.; Rudser, K.; Atkins, D.L.; Berg, R.; Osmond, M.H.; Bulger, E.M.; Davis, D.P.; Schreiber, M.A.; Warden, C.; ROC Investigator. The availability and use of out-of-hospital physiologic infor-mation to identify high-risk injured children in a multisite, population-based cohort. Prehosp. Emerg. Care. 2009, 13, 420-431. [CrossRef]

42. Fleming, S.; Gill, P.; Jones, C.; Taylor, J.A.; Van den Bruel, A.; Heneghan, C.; Roberts, N.; Thompson, M. The Diagnostic Value of Capillary Refill Time for Detecting Serious Ill-ness in Children: A Systematic Review and Meta-Analysis. PLoS ONE 2015, 10, e0138155. [CrossRef]

43. Studnek, J.R.; Brown, L.R.; Shah, M.I.; Fumo, N.; Hansen, M.; Lerner, E.B. Validity of the Pediatric Early Warning Score and the Bedside Pediatric Early Warning Score in Classifying Patients who Reguiqre the Resources of a Higher Level Pediatric Hospital. Prehosp. Emerg. Care 2020, 24, 341-348. [CrossRef]

44. Lang, E.S.; Spaite, D.W.; Oliver, Z.J.; Gotschall, C.S.; Swor, R.A.; Dawson, D.E.; Hunt, R.C. A National Model for Developing, Implementing, and Evaluating Evidence-based Guidelines for Prehospital Care. Acad. Emerg. Med. 2012, 19, 201-209. [CrossRef]

45. Institute of Medicine (U.S.). Committee on the Future of Emergency Care in the United States Health System. In Emergency Care for Children: Growing Pains; National Academies Press: Washington, DC, USA, 2007.

46. Institute of Medicine (U.S.). Committee on the Future of Emergency Care in the United States Health System. In Hospital-Based Emergency Care: At the Breaking Point; National Academies Press: Washington, DC, USA, 2007.

47. Tennessee Department of Health Board for Licensing of Health Care Facilities. Standards for Pediatric Emergency Care Facilities. 2016. Available online: http:/ / cecatn.org/wp-content/uploads/2018/04/Standards-for-Peds-Emergency-Care-Facilities.pdf (accessed on 27 June 2021).

48. Camargo, A.; Boggs, K.M.; Auerbach, M.; Freid, R.D.; Sullivan, A.F.; Espinola, J.A.; Camargo, C.A., Jr. National Study of Self-reported Pediatric Areas in United States General Emergency Departments. Acad. Emerg. Med. 2018, 25, 1458-1462. [CrossRef]

49. Gausche-Hill, M.; Wiebe, R.A. Guidelines for preparedness of emergency departments that care for children: A call to action. Pediatrics 2001, 107, 773-774. [CrossRef] 